\title{
Features of the population organization of Myricaria bracteata in the riverbed of the Ursul River (Gorny Altai)
}

\author{
Elena M. Lyakh*, Alexey Yu. Astashenkov \\ Central Siberian Botanical Garden SB RAS, 630090 Novosibirsk, Russia
}

\begin{abstract}
The article represents the analysis of the ontogenetic composition and demographic parameters of 3 cenopopulations of Myricaria bracteata in the riverbed of the Ursul River (Central Altai). It was found that the ontogenetic structure and density of individuals depend on the degree of formation of the phytocenosis and the influence of abiotic factors (features of the substrate, river bend). The invasive cenopopulation formed in a bend of the river in the absence of a phytocenotic pressure; the young normal cenopopulation formed in the river deflection on the grasscover stony shore, and the invasive-regressive cenopopulation formed on an island washed by the river.
\end{abstract}

\section{Introduction}

The littoral of any water area is one of the dynamic zones that have a significant impact on coastal-aquatic vegetation. The study of the biology and population organization of fluviaphytes - plants that have adapted to sharp short-term flood flows - is one of the main tasks in ecology and has both theoretical and practical significance. Myricaria bracteata Royal (family Tamaricaceae) grows as part of plant groups in river floodplains, and acts as one of the pioneering shrubs species providing the accumulation of the upper soil horizon. This species can be used as a universal model object for the constructing of succession series reflecting the mechanisms of overgrowing of river coastlines. The work objective is to study the population organization of $M$. bracteata in the meander of the Ursul River.

\section{Materials and methods}

M. bracteata is a geoxyl shrub, widespread in Central Asia, as well as in the mountains of East Kazakhstan and Gorny Altai. The species grows along rocky-sandy shores of mountain rivers, pebbles, and drying up beds of mountain rivers and streams [1]. Three population locus (CP) of M. bracteata in the meander of the Ursul River (low right bank), near village Tenga (Shebalinsky Distr.) were researched.

\footnotetext{
*Corresponding author: 1lyakhl@ rambler.ru
} 
CP1 was studied in river bend on a gentle sandy-pebble open alluvial bank 10-15 m width, which is periodically flooded with water. The monodominant community of Myricaria bracteata grew along the water level.

CP2 was studied in river deflection downstream on elevated sandy-pebble shore with shrub and grass vegetation. The formed community contained of the individuals of Populus tremula L., Salix pentandra L.; shrubs Salix viminalis L., Salix rorida Lacksch., Pentaphylloides fruticosa (L.) O. Schwarz, Artemisia laciniata Willd; herbaceous species Festuca rubra L., Alopecurus pratensis L., Deschampsia cespitosa (L.) Beauv., Filipendula ulmaria (L.) Maxim., Songuisorba officinalis L.

CP3 was studied in sandy-pebble island with a rising bank towards the river flow. The area of island was $15 \mathrm{~m}^{2}$. The island was overgrown unevenly and the phytocenosis was formed by the shoots of Populus tremula and Salix viminalis; and herbaceous species Poa pratensis L., Phleum pretense L., Alopecurus pratensis L., Taraxacum officinale (L.) Webb ex. F. H. Wigg.

The main population-ontogenetic methods [2,3] were used. The ontogenetic spectrum is described based on accounting at least 30 sites by $2 \mathrm{~m}^{2}$ in size (the results obtained were converted to $1 \mathrm{~m}^{2}$ ) on transects along and across a riverbed in a regular way. An individual (genet) was applied as a counting unit. The individuals ontogenetic state based on qualitative and quantitative morphological characters have been described by authors earlier [4]. The population type is determined using classifications by A.A. Uranov and O.V. Smirnova [5] and "delta-omega" by L.A. Zhivotovsky [6]. The following demographic characteristics were used as integral parameters: $\Delta$ - age index [7] and $\omega$ efficiency index [6]. The ecological density is determined on the number of individuals per a habitable space unit [8].

\section{Results and discussion}

Previously, it was found, the ontogenesis of $M$. bracteata individuals complete, plants consistently go through all ontogenetic states (p-s); morphrogenesis includes two phases: primary escape, primary bush. As a result of the damage to the bush, ramets are formed, which take root and go through their own ontogeny. The total duration of ontogenesis does not exceed 35 years. The structure of adult individuals is built by the development of perennial orthotropic skeletal axes. The architecture of the unit consists of five subdominant axes [9].

The analysis of demographic indicators and ontogenetic structure identified features of the population organization of loci (Fig. 1).

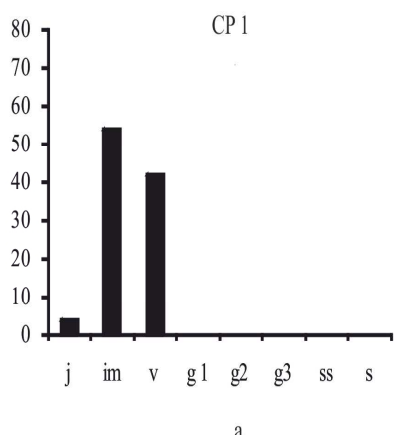

a
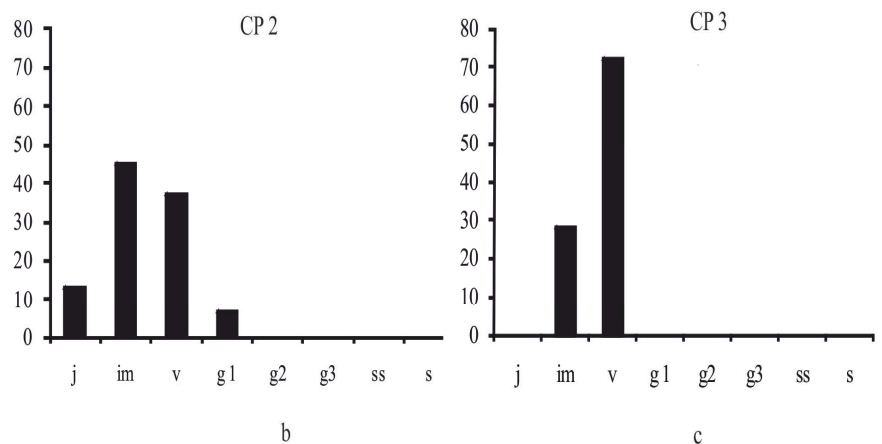

Fig.1. Ontogenetic spectra of the CP of Myricaria bracteata. X-axis - ontogenetic states; Y-axis content of ontogenetic groups, $\%$ 
The ontogenetic spectrum of CP1 in river bend, which is periodically flooded with water, is incomplete left-sided with a maximum on virginile individuals $(v)-72 \%$, with a large proportion of immature ones $(\mathrm{im})-53.5 \%$, and with an insignificant proportion of juvenile individuals $(j)-4.5 \%$ (Fig. 1a). This type of spectrum describes the invasion of the cenopopulation that occurres as a result of seed renewal and rapid rates of development of individuals in the pregenerative period. The height of some immature and virginile individuals in CP 1 exceeded $25-50 \mathrm{~cm}$. CP is young, $\Delta=0.06 ; \omega=0.27$ according to "delta-omega' classification. The presence of a pregenerative fraction and the absence of a generative group and ontogenetic following states make it possible to classify CP 1 as invasive. The average of density of individuals was 16.4 samples $/ \mathrm{m}^{2}$ and density was decreasing from 132 to 2 specimens $/ \mathrm{m}^{2}$ along the coast from a wide bend to a narrow bend of the river.

CP2 was studied in the river deflection on the stony shore with shrub and grass vegetation, and it was characterized by a large set of ontogenetic fractions (Fig. 1b) in contrast to CP1.

The ontogenetic spectrum of CP2 is incomplete left-sided with a peak on immature individuals $(\mathrm{im})-43 \%$. The high content of the pregenerative fraction, including virginile $(v)-37 \%$ and juvenile $(\mathrm{j})-13 \%$ individuals, reflects a good seed restoration of the species. The elevated coastal zone with shrubs (Salix viminalis, $S$ rorida, S. pentandra, Pentaphylloides fruticosa) and the accumulated soil in the substrate favorably affected the accumulation of $M$. bracteata individuals. This formed plant community was protecting $M$. bracteata from floods, however, shading and grass-covered were reduceing the overall size of the plants. The height of immature plants ranged from 1.5 to $15 \mathrm{~cm}$, the height of virginile plants is $15-20 \mathrm{~cm}$. The presence of a young generative group represents the CP2 as normal, young $(\Delta=0.08 ; \omega=0.29)$ capable of a generation turnover and further development. The density of individuals averaged 12.6 samples $/ \mathrm{m}^{2}$ and it fluctuated depending on the degree of grass-covered of the substrate and the presence of Pentaphylloides fruticosa and Salix viminalis shrubs were restrained the dispersal of $M$. bracteata. The highest density of M. bracteata $\left(33 \mathrm{samples} / \mathrm{m}^{2}\right)$ was noted in a sparse phytocenotic environment.

The ontogenetic spectrum of CP3, located on the island, is incomplete left-sided. The accumulation of individuals of the pregenerative fraction on the island was associated with the introduction of genets from the nearest river bank and the high survival rate of the young growth. Despite the fact that studied CP is young $(\Delta=0.14 ; \omega=0.39)$, regular floods and leaching of immature plants prevent the development of CP. The virginile individuals had an insignificant height of $5-30 \mathrm{~cm}$. The abiotic factors adversely affected the emergence of a generative group, which lead to population regression. Thus, the presence of only two fractions in CP (Fig. 1c) with a predominance of virginile individuals (v) $72 \%$ as a result of invasion characterizes $\mathrm{CP} 3$ as regressively invasive, incapable of selfmaintenance. The density of individuals was insignificant $\left(7.3 \mathrm{samples} / \mathrm{m}^{2}\right)$, and an increase in numbers was noted towards the raised coast, where individuals were preserved among stones and protected by young growth of shrubs.

\section{Conclusions}

Thus, the studied cenopopulations of $M$. bracteata reflects the influence of abiotic (river floods) and biotic (phytocenotic environment) factors on the processes of population development and the mechanism of overgrowing of the meandering river bank. In the meander the Ursul River, the invasive CP of M. bracteata forms on a gently flooded open bank in the river bend, and the young normal CP develops in the river deflection on the grass-cover stony shore. The regressive invasive $\mathrm{CP}$ is formed on a river island subject to regular floods. 
The work was carried out within the framework of the state assignments No AAAA-A21121011290027-6 and AAAA-A21-121011290026-9 of the Central Siberian Botanical Garden of the SB RAS

\section{References}

1. E. G. Bobrov, Bot. J. 52, 7 (1967)

2. A. A. Uranova, T. I. Serebryakova (eds.) Cenopopulations of plants (basic concepts and structure) (Moscow, 1976)

3. T. I. Serebryakova, T. G. Sokolova (eds.) Cenopopulations of plants (essays on population biology) (Moscow, 1988)

4. E. M. Lyakh, Flora of As. Rus. 2 (2013)

5. A. A. Uranov, O. V. Smirnova, Bull. Moscow Soc. Natur. Explor. Sect. Biol. 74 (1969)

6. L. A. Zhivotovsky, Ecology 1 (2001)

7. A. A. Uranov, Sci. Rep. High. Schools. Biol. Sci. 2 (1975)

8. Yu. Odum, Ecology (Moscow, Mir, 1986)

9. A. Astashenkov, E. Lyakh, BIO Web of Conferences 24 (2020) 